\title{
Análise do espaço e da cultura material no extinto Terreiro da Gomeia (Duque de Raxias/RJ): um estudo etnoarqueológico
}

\author{
Rodrigo Pereira ${ }^{1}$ \\ E-mail: rodrigopereira.cso@uol.com.br
}

\begin{abstract}
Resumo: O presente artigo versa sobre a proposta de estudo em etnoarqueologia que visa elucidar como se forma o registro da cultura material em terreiros de candomblé extintos e/ou abandonados, pesquisa que se encontra em desenvolvimento em projeto de doutoramento. Para tanto, utilizaremos como estudo de caso o extinto Terreiro da Gomeia (Duque de Caxias/RJ)
\end{abstract}

Abstract: This article deals with the study proposal in ethnoarchaeology aimed at elucidating how it forms the registration of religious communities in material culture of extinct Candomblé and / or abandoned, research is in developing doctoral project. Therefore, we will use a case study of the extinct Terreiro Goméia (Duque de Caxias/RJ).

Resumen: Este artículo trata de la propuesta de estudio en etnoarqueología que pretende dilucidar cómo los formularios de inscripción en la cultura material de yardas Candomblé extintos y / o abandonados, la investigación es en el desarrollo de proyectos de doctorado. Por lo tanto, vamos a utilizar un estudio de caso de la extinta Terreiro de la Goméia (Duque de Caxias / RJ).

Palavras-chaves: Etnoarqueologia; Registro Arqueológico; Cultura Material; Candomblé; Espaços Edificados, Rituais e Profanos.

Keywords: Ethnoarchaeology; Archaeological record; Material Culture; candomblé; built spaces, rituals and profane.

Palabras clave: etnoarqueología; Registro arqueológico; Cultura material; Candomblé; Espacios construidos, rituales y profanos.

\section{Introdução}

\begin{abstract}
${ }^{1}$ Doutorando em Arqueologia (Museu Nacional da Quinta da Boa Vista (UFRJ), Mestre em Arqueologia (Museu Nacional da Quinta da Boa Vista (UFRJ), Mestre em Ciências Sociais (UERJ). Pesquisador de religiões e religiosidades,em especial das religiões afrobrasileiras.Em Antropologia pesquisa 0 candomblé debatendo micro política em terreiros, eventos de sucessão e temas relacionados àliminaridade. Quanto a arqueologia pesquisa, pela etnoarqueologia, elementos da cultura material e espaços edificados, rituais e profanos em casas de candomblé, bemcomo a formação e expansão dessa religião no estado do Rio de Janeiro. Possui ainda experiência na pesquisa de elementos ligados a etnicidade, rituais de passagem, história da imigração pomerana e alemã para o estado do Espírito Santo e historiografia do luteranismo no Brasil e Espírito Santo.
\end{abstract}


O presente artigo versará sobre as contribuições que a Etnoarqueologia dará a um estudo de caso em uma casa de candomblé. Utilizaremos o extinto Terreiro da Gomeia, em Duque de Caxias (RJ) como lócus de aplicação desta proposta e indicaremos possíveis resultados que a pesquisa poderá alcançar.

Conforme Franz Boas (2004) a antropologia norte-americana pode ser entendida como a conjunção de quatro campos: Antropologia Cultural/Social, a AntropologiaBiológica/Bioarqueologia, a Linguística e a Arqueologia. Esta visão somatória é denominada de Four Fields (TRIGGER, 2009), ou Quatro Campos. Ela tem sido uma das vertentes da Arqueologia e da Antropologia adotadas pelo Museu Nacional da Quinta da Boa Vista, permitindo a pesquisadores como Luiz de Castro Faria (1999) e Tania Andrade Lima (1994), atuarem pelo Four Fields ${ }^{2}$. Seguindo esta perspectiva, analisaremos o terreiro em questão aplicaremos determinadas metodologias de etnoarqueologia para o estudo deste Axé ${ }^{3}$

\section{O extinto Terreiro da Gomeia: Pequeno histórico}

Localizado na Rua General Rondon, nº 360, Bairro de Copacabana, Duque de Caxias, o Terreiro da Gomeia foi fundado na década de 1940 por João Alves Torres Filho, o "Joãozinho da Gomeia". De origem étnico-religiosa Angola, o local possui certa quantidade de produções acerca da casa e de seu dirigente (como por exemplo: Lody \& Silva, 2002; Landes, 2002; Nascimento, 2003; Silva, 2010; Gama, 2012; Gama, 2013; Mendes, 2014). Outros dados advêm de fontes orais, jornais veiculados durante o funcionamento da casa e alguns poucos sites na internet. Em 2012, o Instituto do Patrimônio Histórico e Artístico (IPHAN), em seu Inventário de Referências culturais dos Terreiros Tradicionais de Candomblé do Rio de Janeiro (INRC), destacava sobre o local:

João Alves Torres Filho, o Joãozinho da Gomeia, ficou famoso por sua postura polêmica e seu sucesso incomum para um sacerdote do rito angola. Por diversas vezes se apresentou em público[incorporado] com seu orixá,

\footnotetext{
${ }^{2}$ Há de ser destacado que, para além da matriz arqueológica ligada à antropológica, ocorre ainda a matriz ligada à história e arte. Esta segunda tem maior alcance entre arqueólogos europeus. Atualmente, apesar da introdução de outras disciplinas, como a semiótica, a Arqueologia ainda responde e se refere como ciência a estas duas vertentes ou tradições epistemológicas.

${ }^{3}$ Para fins da construção deste artigo, frisamos que os termos "terreiro", "casa de candomblé" e "Axé" serão utilizados como que possuindo a mesma significação para os locais de cultos das religiões afrobrasileiras. Adotaremos as sinonímias para que o texto não seja repetitivo no uso do termo "terreiro". Assim, a palavra "Axé" será grafada em maiúscula ao indicar estes locais. A equivalência é indicada por Cacciatore (1988).
} 
atitude que era desaprovada por sacerdotes e sacerdotisas. Ficou famoso também por ser um ótimo bailarino e por assumir publicamente sua homossexualidade já nas primeiras décadas do século XX. Aos 26 anos, Joãozinho assumiu a chefia de seu terreiro, ainda em Salvador (sua cidade natal), localizado na ladeira da pedra. Posteriormente abriu seu terreiro na rua que Ihe daria o nome, a rua da Gomeia [na mesma cidade]. Foi com a sua mudança para o Rio de Janeiro, onde se instalou na cidade de Duque de Caxias, que Joãozinho atingiu o auge de sua fama, e em 1971 era o pai de santo mais conhecido do país. Entretanto, nunca conseguiu superar as críticas do povo de santo, que não reconhecia em suas atitudes ousadas e seu temperamento transgressor um digno pai de santo. Uma passagem que marcou fortemente sua trajetória foi quando saiu pelas ruas no carnaval de 1956, vestido de "Vedete Arlete", nesse episódio, Joãozinho foi duramente criticado pelas mães de santo da Bahia e pela Federação Umbandista do Rio de Janeiro, o que acabou the rendendo uma matéria na revista "O Cruzeiro", cujo título era: "Joãozinho da Gomeia no tribunal da umbanda". Seu terreiro em Duque de Caxias ganhou popularidade não somente entre o povo de santo, mas diversos segmentos sociais que visitavam a casa pela riqueza e beleza de seus rituais. nas festas mais famosas, havia uma área nobre dedicada a receber as pessoas mais influentes - políticos da baixada fluminense. conta-se que até a sogra de Juscelino Kubitschek frequentou suas festas. Joãozinho se tornou o grande responsável pela expansão do candomblé no sudeste, a partir de 1950. [...] Depois de sua morte, por conta de um tumor cerebral em 1971, seu terreiro em Duque de Caxias não foi mantido. Após disputas de poder - uma menina de dez anos teria sido indicada para dar continuidade a casa, o que desagradou à maioria - e o caboclo pedra preta [sua entidade guia] não teve sucessor para representá-lo (Pereira, et alii, 2012: s/p.).

A antropóloga Ruth Landes, em sua obra A cidade das Mulheres(2002), avultava a homossexualidade do dirigente e a ofensa que seria um homem no comando de terreiros frente ao que a pesquisadora denominou de "Matriarcado Nagô" quanto a proeminência das mulheres na direção dos axés da Bahia:

Há um simpático e jovem pai Congo, chamado João, que quase nada sabe e que ninguém leva a sério, nem mesmo as suas filhas de santo (...); mas é um excelente dançarino e tem certo encanto. Todos sabem que é homossexual, pois espicha os cabelos compridos e duros e isso é blasfemo. - Qual! Como se pode deixar que um ferro quente toque a cabeça onde habita um santo! (LANDES, 2002: 65).

A grande fama e as polêmicas cercaram a vida de Joãozinho, fosse por sua postura enérgica com seus filhos de santo ou mesmo visto como relapso com os mesmos (GAMA, 2012). Cronologicamente, a vida de Joãozinho pode ser resumida conforme a tabela 1, a 
seguir. Aparentemente o dirigente e a casa eram alvos de muitas publicações, como as presentes na Revista O Cruzeiro, o que deu enorme notoriedade ao dirigente e a casa. Em especial, muito recorriam a casa não para a consulta com os orixás, mas sim com a entidade cabocla do dirigente (o Caboclo Pedra Preta). Por meio de notícias veiculas e de estudos acadêmicos (Lody \& Silva, 2002; Nascimento, 2003; Silva, 2010; Gama, 2012; Gama, 2013 e Mendes, 2014) sabe-se que após a morte do dirigente em 1971 instaurou-se um conflito entre duas alas que disputavam o comando da casa.

Conforme jornais como O Globo e Última Hora, de uma lado estava lleci da Silva, filha de Oxum e a lalaxé da casa (pessoa que cuida dos espaços físicos e conservação dos bens do terreiro), sendo aclamada por unanimidade para a direção. De outro lado estava Ceci, ou Sandra Regina de Oxumarê, de apenas 7 anos, a qual foi indicada pelos búzios como sucessora.

Após o conflito instaurado, já que a justiça havia impedido que uma menor assumisse o comando, Sebastião Paulo da Silva, ou Gitadê, rompe com a casa e se transfere, seguido de lleci e mais alguns filhos de santo do terreiro, para São Paulo. Em terras paulistas ele funda o Terreiro da Gomeia de São Jorge. Os estudos indicam que, após o entrave, a casa em desacordo continuou aberta por poucos anos, pois Sandra Regina teria optado por não assumir o comando das atividades, o que levou o terreiro ao seu fechamento e abandono.

Em 2012 as pesquisas de Pereira, et all, registraram que o antigo terreiro serve como campo de futebol e área de descarte ritual de objetos dos cultos afro-brasileiros, possuindo ainda algumas estruturas do antigo axé. Isso é indicativo que o local mantenha certo caráter religioso e mesmo de referencial para o "povo de santo" que o utiliza como verificado por Pereira, et alli, 2012. A figuras 1 apresenta o atual estado do Axé.

Tabela 1. Cronologia da vida de Joãozinho da Gomeia

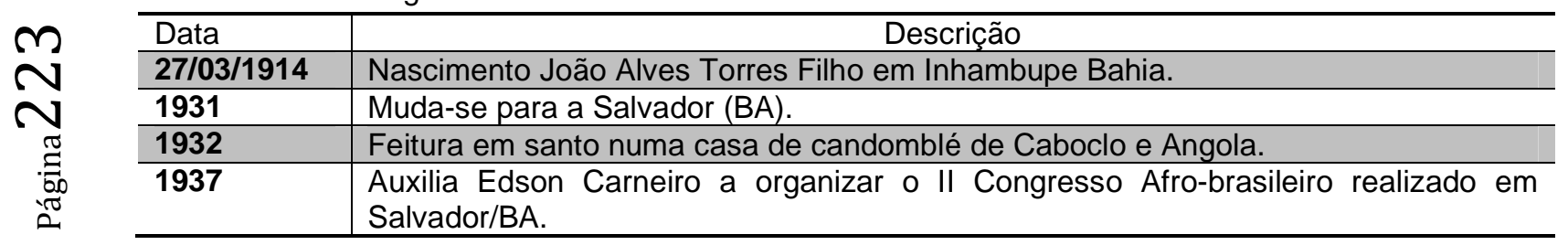

\begin{tabular}{|l|l|l|l|l|l|l|}
\hline (C Rev. Arqueologia Pública & Campinas, SP & v.9 & No.(11) & p.220-230 & suplemento & ISSN 2237-8294 \\
\hline
\end{tabular} 


\begin{tabular}{l|l}
\hline 1940 & $\begin{array}{l}\text { Abre seu primeiro terreiro ainda em salvador que ficava na Ladeira da Pedra. Logo } \\
\text { depois, mudou-se para a rua que o tornaria famoso - a Rua da Gomeia - que ficava } \\
\text { no bairro de São Caetano, Cidade Baixa, onde tocava um candomblé com mistura } \\
\text { Angola e Keto. }\end{array}$ \\
\hline 1942 & $\begin{array}{l}\text { Muda-se para o Rio de Janeiro, então chamado estado da Guanabara morando Rua } \\
\text { Avenida Paris, 55, Bonsucesso, mas retorna para a Bahia em seguida. }\end{array}$ \\
\hline 1946 & $\begin{array}{l}\text { Muda-se em definitivo para o Rio de Janeiro e funda o Terreiro da Gomeia em } \\
\text { Duque de Caxias. }\end{array}$ \\
\hline 1971 & Falecimento de Joãozinho da Gomeia. \\
\hline
\end{tabular}

Fonte: Pereira, et all, 2012.

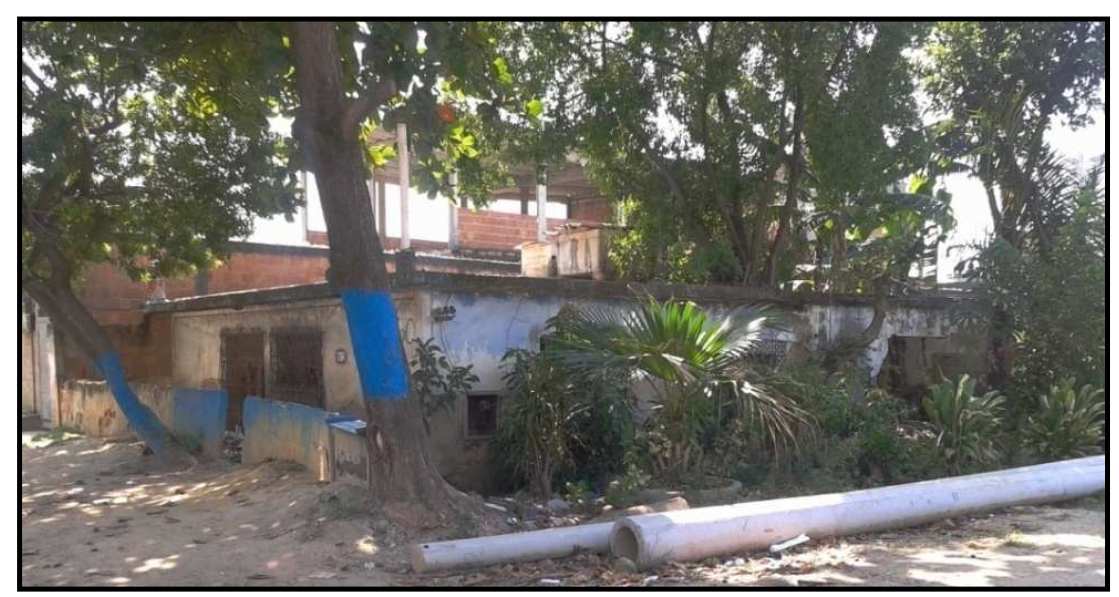

Figura 1. Frente da antiga residência de Joãozinho da Gomeia. Fonte:Pereira, et alli, 2012: s/p

\section{A Etnoarqueologia aplicada ao caso}

Para o estudo deste Axé duas medidas arqueológicas podem contribuir para o estudo: as escavações dos remanescentes estruturais do local e sua cultural material ${ }^{4}$ associada, bem como a aplicação da reconstrução da divisão dos espaços sagrados, rituais e profanos pelos modelos de ocupação espacial propostos por Hiller \& Hanson (1984) e Pereira (2013).

Para a área em questão adotaremos o modelo de escavação denominado por Lloret, (1997) de open-area, baseado na suposição da escavação de amplas superfícies de terreno. Esta metodologia de escavação considera que "toda a escavação devia aspirar à condição de escavação total" (BARKER, 1982: 68), tendo esta ideia dois significadoscomplementares: primeiro, que toda a estação arqueológica deverá ser escavada, não recorrendo a secções ou trincheiras de amostragem (BARKER, 1982); segundo, que toda a área da estação deveria ser escavada, ou seja, que não deveriam ser deixadas interrupções físicas no interior da área escavada, pois, regra geral, "um sítio arqueológico é provavelmente três vezes mais complexo em plano do que parece ser em secção" (LLORET, 1997: 154).

Nesta metodologia as fácies estratigráficas deixam de ser elementos incluídos no interior da área escavada, passando a estratigrafia a ser representada cumulativamente, através da representação gráfica das interfaces dos diferentes estratos (LLORET, 1997. Ou seja, se observarmos um perfil estratigráfico obteremos uma interpretação dos períodos de ocupação, bem

${ }^{4}$ Por cultura material adotamos o conceito de Deetz (1977), segundo a qual o termo corresponde a qualquer segmento do meio físico modificado por comportamentos culturalmente determinados.

\begin{tabular}{|l|l|l|l|l|l|l|}
\hline (C Rev. Arqueologia Pública & Campinas, SP & v.9 & No.(11) & p.220-230 & suplemento & ISSN 2237-8294 \\
\hline
\end{tabular}


como das práticas sociais que eles podem registrar de forma cumulativa ou somatória no tempo-espaço em que o local foi ocupado. Isto significa dizer que adotaremos para o local o Princípio da Sobreposição (BICHO, 2012), no qual entende-se que "uma camada sedimentar é mais recente do que aquela que ela recobre [...]. Isto significa que, se não tiver havido qualquer alteração após sua deposição, a camada mais antiga está por baixo e a mais recente estará a cobri-la" (BICHO, 2012: 177).

Nas escavações deve-se ser implantada grid alfa numérico de malha arqueológica em toda a área, onde já estarão localizadas as estruturas ainda visíveis. O grid, ou quadra - unidade mínima de escavação, terão as dimensões de 10 metros por 10 metros. Adotando após ele a decupagem total do terreno, ou seja, a escavação de toda a área em níveis estratigráficos naturais $^{5}$ (quando presentes) ou artificiais em intervalos de 10 em 10 centímetros da superfície até identificação de solo sem material arqueológico (o qual denomina-se solo estéril) ${ }^{6}$.

Para a análise da divisão dos espaços serão adotadas técnicas da para a elaboração de uma reconstrução da configuração espacial dos terreiros, identificando onde os espaços rituais (casas de santo, assentamentos e o barracão), os espaços profanos ou de sociabilidade (tais como a moradia do dirigente, locais de atendimento ao público) e o espaço mata (locais com vegetação para uso litúrgico) se localizavam no extinto terreiro da Gomeia. Para tanto, será adotado o modelo tripartido de espaços nos terreiros desenvolvido por Rocha (2000) e as ligações que estes espaços possam ter entre si (HILLER \& HANSON,1984). De forma complementar, as análises realizadas por Pereira (2013) serão de grande valia ao indicar os valores simbólicos e materiais que estes espaços possuem.

A análise do espaço edificado e da cultura material pelo viés arqueológico em casas de candomblé permite uma leitura da interlocução entre o que é pensado, o que é realizado no plano material e o que é expresso em documentos, entrevistas e imagens sobre aquele local. Permite ainda a análise de significados destes lugares sagrados, construídos pelos grupos ao longo dos processos de manutenção da casa, de sua organização espacial, mítico-religiosa e, sobretudo, de como este espaço é negociado entre os membros desses terreiros, no intuito de que expressem mais que uma ideia geral ou modelo de terreiro (como o proposto por Rocha, 2000), mas também uma apropriação e intencionalidade não prevista em modelos ideais pelos que ali transitam enquanto membros. Permite entender os mecanismos de agência, bem como as expressões de sensorialidade na construção da paisagem física e cultural. Assim, a pesquisa adotava a perspectiva de analisar continuidades ou descontinuidades observáveis numa lógica do espaço social (HILLIER \& HANSON, 1984).

Rocha (2000) e Conduru (2010) desenvolveram um "Modelo Nagô de Terreiros" para a descrição dos espaços edificados em terreiros de candomblé. Apesar de centrarem-se em um modelo Nagô, as pesquisas de Pereira (2013) indicam que ele é extensivo para todas as nações do culto a ancestralidade africana. Conforme Rocha (2000) as casas de candomblé

\footnotetext{
${ }^{5}$ Níveis estratigráficos naturais são aqueles em que é possível visualizar a presença de camadas naturais provenientes da própria dinâmica do solo (camadas com diferentes constituições de sedimento visíveis em cor ou textura) ou mesmo da ocupação humana (como camadas de aterro ou a presença de bolsões de descarte de materiais, como lixo ou descartes rituais).

${ }^{6}$ Conforme Mendonça de Souza (1997), o quadriculamento é uma técnica de escavação que consiste me dividir a zona à escavar em quadrículas para facilitar a localização topográfica das evidências arqueológicas.
} 
são compostas por dois espaços bem definidos: a área construída e o terreiro. Sobre estas divisões é que se organizam as suas ocupações e as suas destinações. Rocha (2000) ainda destaca a existência do espaço mata/vegetação que não se enquadra na divisão acima descrita, pois se constitui de uma área vegetal ligada simbolicamente à África e que contém as plantas rituais da casa.

Normalmente esta mata pode ser uma pequena área com plantas (como um jardim), uma capoeira ou vegetação antropizada pelo/a dirigente, ou ainda um vaso com uma ou duas plantas. Não importa o tamanho, mas sim o símbolo ali expresso. Para esta pesquisa adaptase este modelo reconhecendo-se nas casas de candomblé três compartimentos: a área construída (que se divide em espaços públicos e privados quanto à circulação de pessoas), o terreiro/barracão, onde se realizam as festas, como um "microcosmo da África" (BASTIDE, 2001), e a mata ${ }^{7}$.

Desta forma, tanto a descrição do espaço como as análises empreendidas podem ser melhor qualificadas e quantificadas na compreensão da lógica da concepção de ambiente e da cultura material nestes locais. É nesse sentido que Conduru (2010: 191) afirma que "essa estruturação por setores está associada às dinâmicas de suas atividades cotidianas,religiosas, festivas e artísticas, com suas características mais privadas ou públicas", o que permite ao artigo, portanto, adotar tal modelo básico, a ser verificado e debatido, como base de análise para a cultura material e locais edificados analisados. Os espaços edificados dos terreiros, portanto, são analisados nesta tese tendo as seguintes clivagens como focos analíticos de significação e de suporte para a cultura material (vide figura 2).

\footnotetext{
${ }^{7}$ A mata é entendida como edificada no sentido de ser desenvolvida pela ação humana e não como um espaço construído como um cômodo. Ela significa a ação humana intencional, por isso constituinte de representações ou valores para o candomblé.
} 


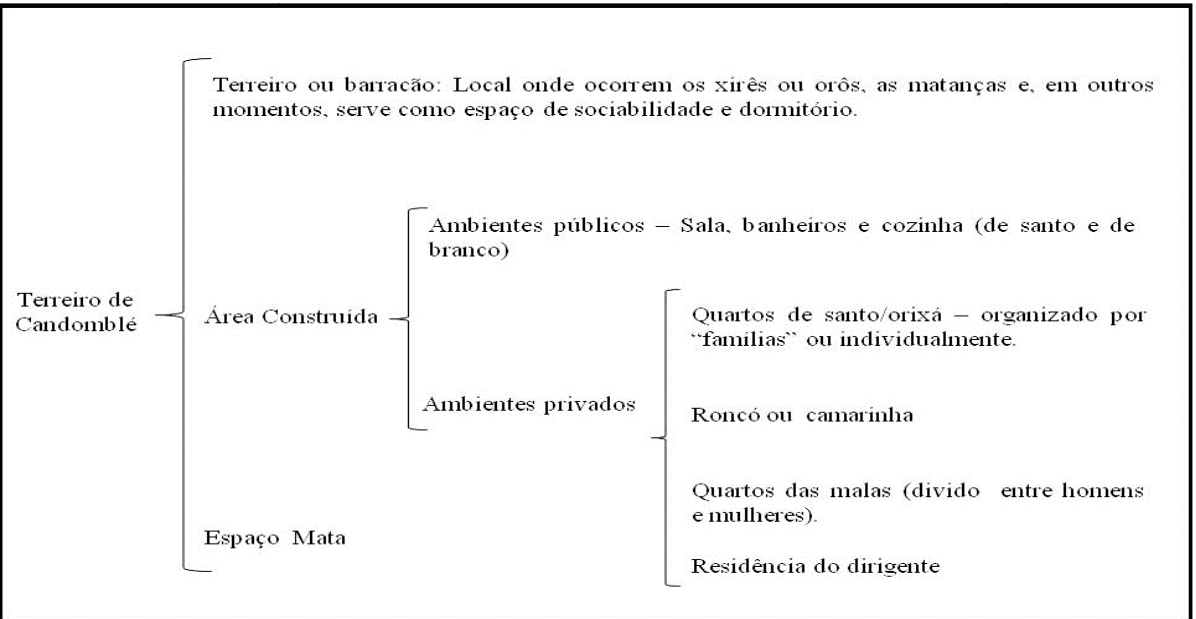

Figura 2. Espaços edificados nos terreiros de candomblé analisados pelo artigo. Fonte: Adaptado de Rocha (2000).

Destaca-se, do modelo de Rocha (2000), a clivagem dos espaços entre públicos e privados, inferindo-se a valoração de uso, ou seja, os ambientes públicos tendem a ser aqueles em que todas as pessoas, membros ou não da casa, podem transitar sem interdições de cunho religiosos. Ao contrário, os ambientes privados se caracterizam pelo uso exclusivo dos membros do culto, sendo proibido a não membros do terreiro. ou mesmo restringido Além do uso ritualístico em quartos de santos, casas de santo ou assentamentos, os ambientes privados contam ainda com um quarto das malas, local onde os filhos de santo têm, cada um, uma mala ou baú onde são acondicionadas roupas, paramentos, objetos de cultos, e mesmo pessoais, ou ainda suas roupas utilizadas durante os rituais, obrigatoriamente brancas devido aos preceitos da religião. Tal quarto serve ainda como local de descanso e como dormitório durante as festas e rituais nos terreiros.

Para a compreensão dos eventos sucessórios na Gomeia e os referentes a formação do registro arqueológico serão adotadas técnicas da História Oral para a elaboração da trajetória da casa (FERREIRA \& AMADO, 2000), bem como os dados etnográficos obtidos por comparações com terreiros em funcionamento (PEREIRA, 2013). Indica-se, para o caso analisado, por exemplo, a realização de entrevistas com ex membros da Gomeia (atualmente residentes no entorno do terreiro), dirigentes de outros Axés que tenham convivido com Joãozinho (como Mãe Maria de Xangô do Axé Pantanal) ou sido iniciados (as) por ele (como o caso de Giselle Cossard de Omindarewá) para a construção de uma planta baixa do terreiro e de seus espaços edificados e rituais.

Por História Oral entendemos, conforme Silva (2009), que ela seja aquele ramo da História que está "marcadamente envolvida com as questões da memória humana, tanto coletiva quanto individual. E, nesse sentido, passou a ser um relevante meio de valorização das identidades de grupos sem escrita, por meio da coleta de seus depoimentos e da análise de sua memória, de sua versão do mundo e dos acontecimentos." (SILVA, 2009: 186). Desta forma, concordamos com a assertiva de Thompson (1992: 17): 
A história oral pode dar grande contribuição para o resgate da memória nacional, mostrando-se um método bastante promissor para a realização de pesquisa em diferentes áreas. É preciso preservar a memória física e espacial, como também descobrir e valorizar a memória do homem. A memória de um pode ser a memória de muitos, possibilitando a evidência dos fatos coletivos.

Percebemos que o resgate da espacialidade da casa analisada, para além das técnicas de Arqueologia, terá grande aporte se utilizarmos a oralidade para a compreensão de como os indivíduos se relacionavam com os espaços edificados e rituais, bem como entre si (enquanto um grupo social e religioso com regras específicas de trânsito dentro do Axé). De Alberti (1989) é valido trazer à discussão o campo da validação desta história, bem como a capacidade que ela guarda em se tornar uma "história oficial":

A história oral apenas pode ser empregada em pesquisas sobre temas contemporâneos, ocorridos em um passado não muito remoto, isto é, que a memória dos seres humanos alcance, para que se possa entrevistar pessoas que dele participaram, seja como atores, seja como testemunhas. É claro que, com o passar do tempo, as entrevistas assim produzidas poderão servir de fontes de consulta para pesquisas sobre temas não contemporâneos (ALBERTI, 1989: 04) [grifos nossos].

Entendemos, conclusivamente, que ela não seja uma disciplina ou instrumental isolado de pesquisa, mas sim "um conjunto de técnicas, um método, para a pesquisa histórica e o tratamento documental" (SILVA, 2009: 187). Assim, também serão consultados os arquivos do Museu do Folclore, com o intuito de rastrear notícias veiculadas em jornais e revistas da época de vigência da casa sobre o referido dirigente; bem como analisar as formas com que a sociedade noticiou sua morte e a conflito instaurado.

\section{Considerações finais}

Explicitamos neste artigo como a Etnoarqueologia será aplicada para uma compreensão de um estudo de caso de religiões afro-brasileiras que aborde a formação do registro arqueológico e debate se ele tende ou não a se forma rem locais como o proposto. Ressaltamos que a pesquisa encontra-se em fase de elaboração, logo, não podemos apresentar ainda resultados das escavações e da proposta feita.

\section{Referências Bibliográficas}

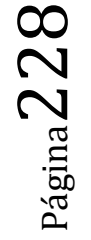

ALBERTI, V. História oral:a experiência do CPDOC. Rio de Janeiro: Fundação Getúlio Vargas, 1990, $197 \mathrm{p}$. 
BASTIDE, Roger. O candomblé da Bahia:rito nagô. São Paulo: Companhia da Letras, $2001.400 \mathrm{p}$.

BARKER, Philip, Techniques of Archaeological Excavation.2. ed. Londres: Batsford, 1982, 138 p.

BICHO, Nuno Ferreira. Manual de arqueologia pré-histórica. 2. ed. rev. Lisboa: Edições 70, 2012, $541 \mathrm{p}$.

BOAS, Franz. Antropologia cultural. Rio de Janeiro: Zahar, 2004, 109 p.

CASTRO FARIA, Luiz. Antropologia: escritos exumados2: dimensões do conhecimento antropológico. Niterói: UFF, 1999, 438 p.

CONDURU, Roberto. Das casas às roças: comunidades de candomblé no Rio de Janeiro desde o fim do século XIX. In: Revista Topoi, v. 11, n. 21, jul.-dez., p. 178-203, 2010.

DEETZ, James. In Small Things Forgotten: The Archaeology of Early American Life. New York: Anchor Books, 1977, 260 p.

FERREIRA, Marieta de Moraes; AMADO, Janaína. Usos e abusos da história oral. 3aㅡ ed. Rio de Janeiro: FGV, $2000.277 \mathrm{p}$.

GAMA, Elizabeth Castelano. Mulato, homossexual e macumbeiro:que rei é este? Trajetória de Joãozinho da Gomeia (1941-1971). p. 205 Dissertação (mestrado). Programa de Pósgraduação em História da Universidade Federal Fluminense, 2012.

. Uma trajetória de muitas histórias: João da Gomeia e o conflito entre Candomblé e Umbanda nos anos dourados. In: Anais do XXVII Congresso Nacional de História: conhecimento histórico e diálogo social. Natal, p. 1-12,julho de 2013

HILLIER B. \& HANSON, J. The social logic of space. Cambridge: Cambridge University Press, $1984,281 \mathrm{p}$.

LANDES, Ruth. A cidade das mulheres. 2. ed. Rio de Janeiro: UFRJ. 2002, 352 p.

LIMA, Tânia Andrade. De morcegos e caveiras a cruzes e livros: a representação da morte noscemitérios cariocas do século XIX. In: Anais do Museu Paulista, v.2. São Paulo, p. 87$150,1994$.

LLORET, Sonia Gutiérrez. Arqueología - Introducción a la historia material de las sociedades del pasado. Alicante: Universidad de Alicante - Publicaciones, 1997, 219 p. 
LODY, Raul, e SILVA, Vagner Gonçalves da. Joãozinho da Gomeia: o lúdico e o sagrado na exaltação ao candomblé. In: SILVA, Vagner Gonçalves (org.). Caminhos da Alma: memória afro brasileira. São Paulo: Summus, p. 153-184,2002.

MENDONÇA DE SOUZA, Alfredo. Dicionário de arqueologia. Rio de Janeiro: ADESA, 1997, $140 \mathrm{p}$.

MENDES, Andrea. O rei do candomblé nas páginas da revista: Joãozinho da Gomeia em O Cruzeiro (1967). In: Recôncavo: Revista de História da UNIABEU, Vol. 4 N. 6, p. 58-78, janeiro - junho de 2014.

NASCIMENTO, Andréa. De São Caetano à Caxias: Um estudo de Caso sobre a trajetória do Rei do Candomblé Joãozinho da Gomeia. p.99. Monografia (graduação) em Pedagogia, Universidade do Estado do Rio de Janeiro, 2003.

PEREIRA, Rodrigo; MOURÃO, Tadeu; CONDURU, Roberto; GASPAR, Anderson; RIBEIRO, Maíra. Inventário nacional de registro cultural do candomblé no Estado do Rio de Janeiro. Rio de Janeiro: Musas, 2012, 216 p.

PEREIRA, Rodrigo. Espaço e cultura material em Casas de Candomblé no Rio de Janeiro. p.302. Dissertação (Mestrado em Arqueologia) Museu Nacional da Quita da Boa Vista (UFRJ). 2013.

ROCHA, Agenor Miranda. As nações Kêtu: ritos e crenças: os Candomblés antigos do Rio de Janeiro. Rio de Janeiro: Mauad, 2000, 111 p.

SILVA, Kalina Vanderlei. Dicionário de conceitos históricos. 2.ed., $2^{\underline{a}}$ reimpressão. São Paulo: Contexto, 2009, 439 p.

SILVA, Joselina da. O Negro Baiano Pai Joãozinho da Gomeia: o candomblé de Duque de Caxias na mídia dos anos cinquenta. In: Revista Magistro, Vol. 1 N.1, Rio de Janeiro, p. 3853,2010 .

THOMPSON, Paul. $A$ voz do passado. São Paulo: Paz e Terra, 1992, 44 p.

TRIGGER, Bruce G. A history of archaeological thought. 2. ed. Cambridge: Cambridge University Press, 2009, 730 p.

\begin{tabular}{|l|l|l|l|l|l|l|}
\hline (C Rev. Arqueologia Pública & Campinas, SP & v.9 & No.(11) & p.220-230 & suplemento & ISSN 2237-8294 \\
\hline
\end{tabular}

